\title{
Two new spider species of the genera Glenognatha and Pachygnatha (Araneae: Tetragnathidae) from Japan
}

\author{
Yuki G. Baba* ${ }^{1 *}$ Akio Tanikawa ${ }^{2}$ \\ ${ }^{1}$ Biodiversity Division, Institute for Agro-Environmental Sciences, NARO, 3-1-3 Kannondai, Tsukuba, Ibaraki 305-8604, Japan \\ E-mail:ybaba@affrc.go.jp \\ ${ }^{2}$ Laboratory of Biodiversity Science, School of Agriculture and Life Sciences, The University of Tokyo, 1-1-1, Yayoi, Bunkyo-ku, \\ Tokyo 113-8657, Japan \\ ${ }^{*}$ Corresponding author
}

\begin{abstract}
Two new species of the spider family Tetragnathidae (Araneae) from Japan are described: Glenognatha osawai sp. nov. and Pachygnatha monticola sp. nov. Glenognatha osawai is described on the basis of specimens collected on the Ogasawara Islands (Nakodo-jima and Muko-jima Islands). This new species is similar to G. argyrostilba (O. Pickard-Cambridge 1876) and G. tangi (Zhu, Song \& Zhang 2003) in general appearance and cheliceral morphology, but it can be distinguished by the shapes of conductor, cymbium, and paracymbium of the male palp. Pachygnatha monticola is described from Nagano Prefecture, a mountainous region of Honshu Island. This new species resembles P. quadrimaculata (Bösenberg \& Strand 1906), but it can be distinguished by the morphology of chelicera and fang and by the shapes of embolus and paracymbium of the male palp.
\end{abstract}

Key words - Ogasawara islands, Nagano Prefecture, orb-weaving spiders, Tetragnathidae

\section{Introduction}

The genera Glenognatha Simon 1887 and Pachygnatha Sundevall 1823 (Araneae: Tetragnathidae), which are small orb weaving spiders that live near the ground surface, form closely related monophyletic group (Cabra-Garcia \& Brescovit 2016) and belong to the subfamily Tetragnathinae (Álvarez-Padilla \& Hormiga 2011). The general appearances of these two genera are similar to one another, but they can be distinguished by the structure of male palp, including the shapes of paracymbium, conductor lamina, and embolus, and by the morphological characteristics of female tracheal system (Cabra-Garcia \& Brescovit 2016). Glenognatha and Pachygnatha currently comprise 32 and 43 known species worldwide, respectively (World Spider Catalog 2017), but there is a high probability of finding undescribed species (Cabra-Garcia \& Brescovit 2016).

Few species of these genera are distributed in Japan. In Glenognatha, only G. dentata Zhu \& Wen 1978 has been recorded in Japan, from the Ryukyu Islands (Tanikawa 2009, 2017). In Pachygnatha, only P. tenera Karsch 1879, $P$. quadrimaculata (Bösenberg \& Strand 1906), and P. clercki Sundevall 1823 have been recorded from the main islands of Japan (Tanikawa 2009, 2017). These species are widely distributed across Eurasia, and there are no members of the genera unique to Japan. However, we have recently recognized two undescribed species, each of which belongs to
Glenognatha and Pachygnatha respectively, on the basis of specimens collected in Japan. Here, we describe a new species G. osawai from Muko-jima and Nakodo-jima Islands, part of the Ogasawara Islands located in the western North Pacific and approximately $1000 \mathrm{~km}$ south of mainland Japan (Ito 1998). This is the first record of this genus on the oceanic islands of Japan. Furthermore, we also describe a new species Pachygnatha as P. monticola, on the basis of specimens obtained from a mountainous region of central Honshu.

\section{Materials and methods}

All specimens used in this study were captured by hand and preserved in $75 \%(\mathrm{v} / \mathrm{v})$ ethanol. The morphological features were observed under a stereomicroscope (SMZ1000, Nikon Corp., Tokyo, Japan; or M3Z, Wild Heerbrugg AG, Heerbrugg, Switzerland). All measurements were made by using an ocular micrometer on the stereomicroscope. Photographs were taken with an EOS Kiss X7 digital camera (Canon Inc., Tokyo, Japan) connected to the microscope. The holotypes and paratypes designated in this paper are deposited in the collection of the Department of Zoology, National Museum of Nature and Science, Tokyo. 


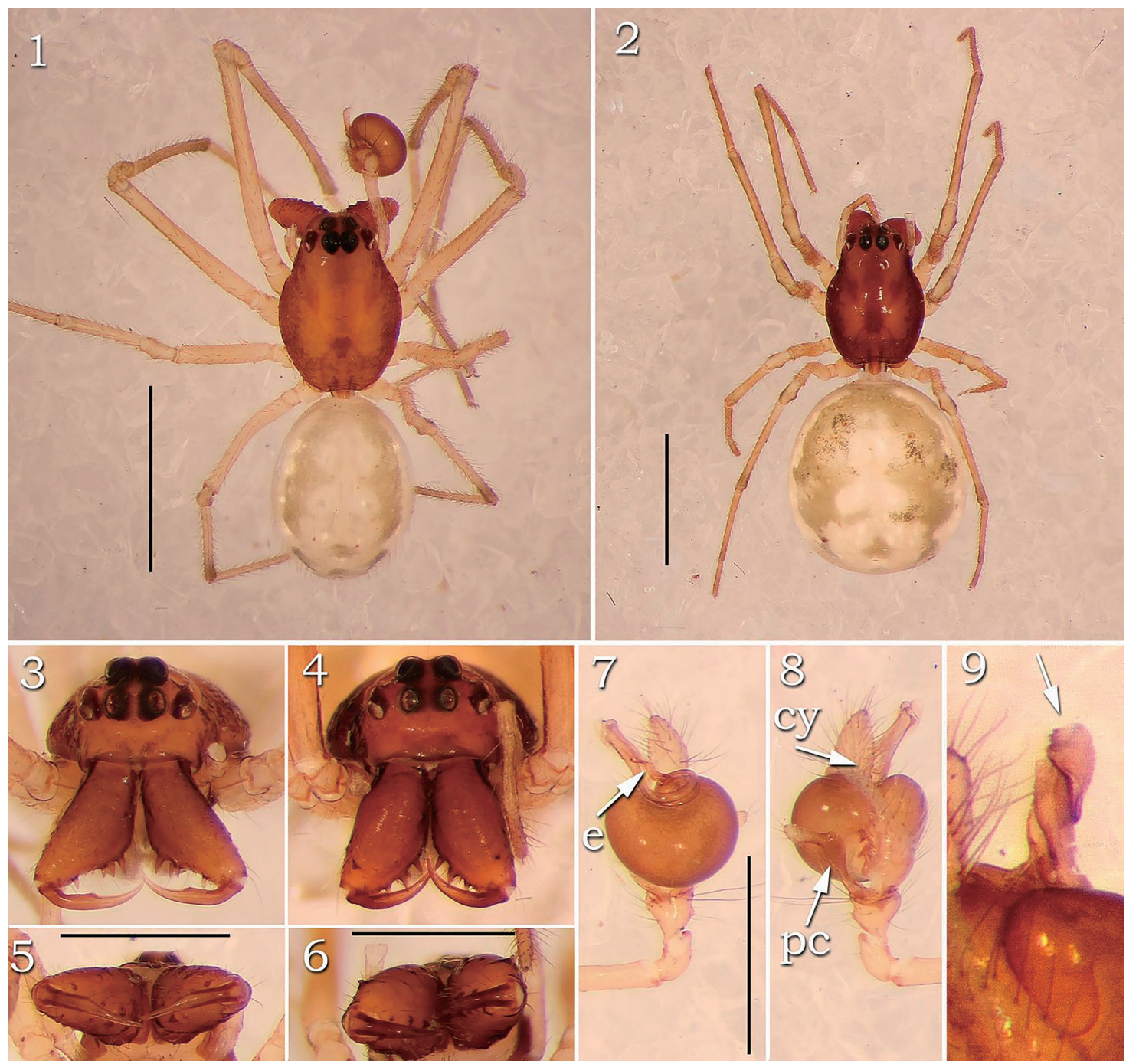

Figs. 1-9. Glenognatha osawai sp. nov. (male holotype and female paratype). 1, habitus of male; 2, habitus of female; 3 , male, frontal view; 4 , female, frontal view; 5 , male chelicera, ventral view; 6 , female chelicera, ventral view; 7-8, male left palp, ventral and dorsal views; 9, conductor of male left palp, dorsal view (arrow indicates the tip of the conductor). Scales = $1 \mathrm{~mm}(1-2) ; 0.5 \mathrm{~mm}$ (3-9). e, embolus; cy, cymbium; pc, paracymbium.

\section{Taxonomy}

Order Araneae Clerck 1757

Family Tetragnathidae Menge 1866

Genus Glenognatha Simon 1887

Glenognatha osawai sp. nov.

(Japanese name: Osawa-hime-ashinagagumo)

(Figs. 1-9)

Type series. Holotype: $\widehat{\partial}, 28-29-\mathrm{VI}-2015$, Muko-jima Island, Ogasawara-mura, Tokyo, Japan. T. Osawa leg. Paratype: 1ㅇ, 20-VII-2013, Nakodo-jima Island, Ogasawara-mura, Tokyo, Japan. T. Osawa leg.

Etymology. The specific name is dedicated to Dr. Takeshi Osawa of the Tokyo Metropolitan University, who collected the type specimens of the new species.

Diagnosis. Glenognatha osawai resembles G. argyrostilba (O. Pickard-Cambridge 1876) and G. tangi (Zhu, Song $\&$ Zhang 2003) in general appearance and cheliceral morphology. Males can be distinguished from those of the latter species by the shapes of conductor, cymbium, and paracymbium on the palp: (1) the tip of conductor in G. osawai is wider than that of G. argyrostilba and its length is greater than that of G. tangi (Fig. 9, arrow); (2) the upper half of cymbium in G. osawai is wider than those of the other two species; (3) the part of paracymbium from the bent portion to the tip is longer than those of the other two species. In females, it is difficult to distinguish species from one another by their appearances.

Description. Based on holotype $\hat{O}$ and paratype $P$.

Coloration and markings. Male and female (Figs. 1-2): 


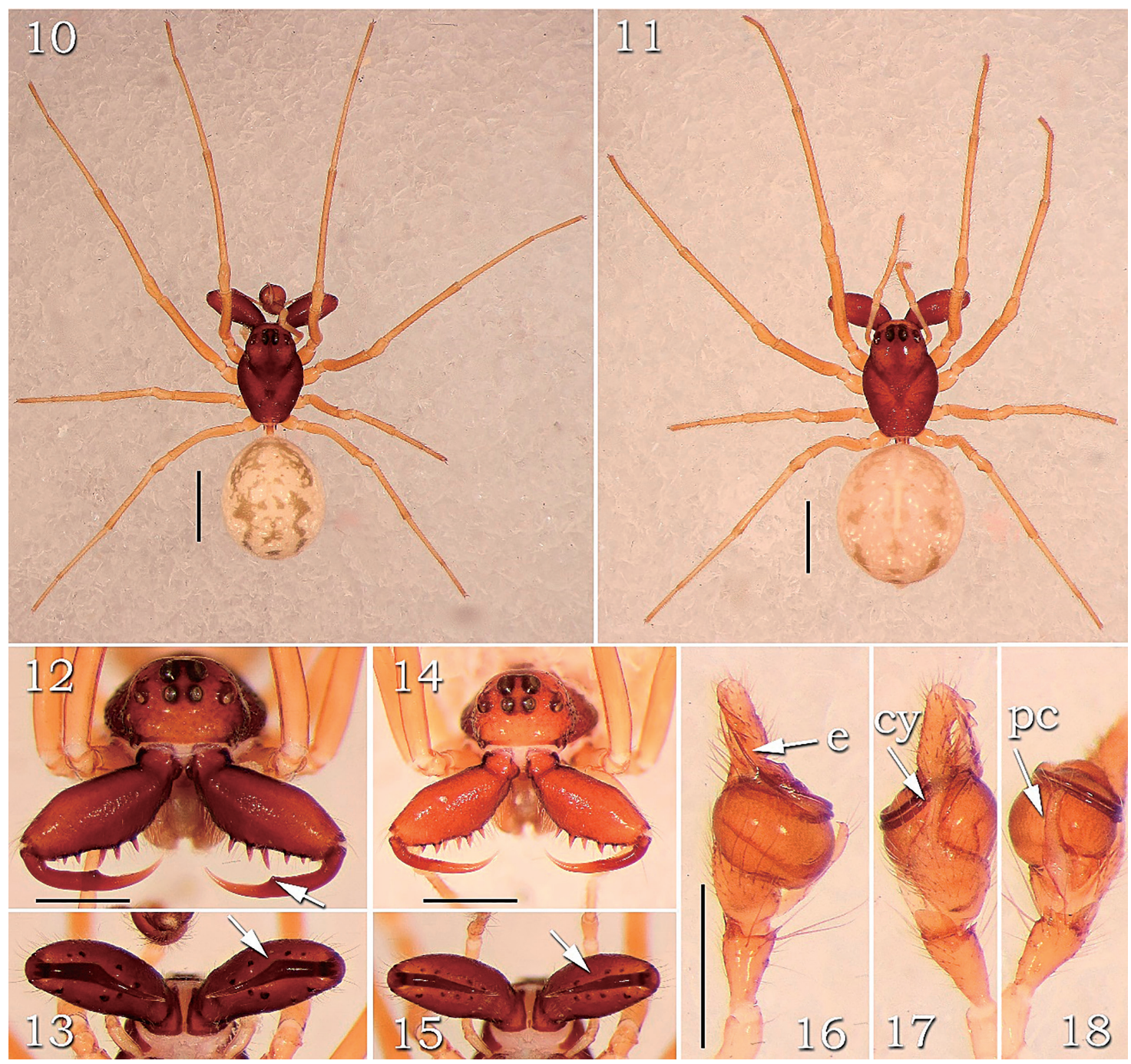

Figs. 10-18. Pachygnatha monticola sp. nov. (male holotype and female paratype). 10, habitus of male; 11 , habitus of female; 12 , male, frontal view; 13 , male chelicera, ventral view; 14, female, frontal view; 15 , female chelicera, ventral view; 16-18, male left palp, ventral, dorsal and retrolateral views. Scales $=1 \mathrm{~mm}(10-11) ; 0.5 \mathrm{~mm}(12-18)$. e, embolus; cy, cymbium; pc, paracymbium.

carapace brown with dark brown markings; dorsum of abdomen light brown, mottled with pale green.

Measurements. $\delta /$ o . Body $2.00 / 2.69$ mm long. Carapace 0.94 / $1.06 \mathrm{~mm}$ long, $0.64 / 0.76 \mathrm{~mm}$ wide. Length of legs (tarsus + metatarsus + tibia + patella + femur $=$ total $): I$, $0.55+0.94+1.12+0.27+1.15=4.03 \mathrm{~mm} / 0.52+0.94+$ $1.06+0.30+1.09=3.91 \mathrm{~mm}$; II, $0.45+0.82+0.94+0.30$ $+1.00=3.51 \mathrm{~mm} / 0.48+0.82+0.94+0.30+1.00=3.54$ $\mathrm{mm}$; III, $0.33+0.45+0.51+0.21+0.70=2.20 \mathrm{~mm} / 0.30$ $+0.48+0.51+0.24+0.63=2.16 \mathrm{~mm} ; \mathrm{IV}, 0.33+0.63+$ $0.72+0.21+1.03=2.92 \mathrm{~mm} / 0.36+0.70+0.81+0.21+$ $0.94=3.02 \mathrm{~mm}$. Abdomen $1.00 / 1.62 \mathrm{~mm}$ long, $0.75 / 1.38$ mm wide.

Male and female. Carapace longer than wide (length divided by width, $1.47 / 1.39$ ). Median ocular area slightly longer than wide (length divided by width, $1.08 / 1.07$ ); posterior width as large as anterior (anterior width divided by posterior width, $1.08 / 0.93$ ). Labium wider than long (length divided by width, $0.43 / 0.50$ ). Sternum slightly longer than wide (length divided by width, $1.06 / 1.05$ ). Length of leg I divided by length of carapace 4.29 / 3.69. Male palp (Figs. 7-9): embolus gently curved, cymbium bent near the middle, conductor enclosing embolus, paracymbium long and spatulate. Abdomen longer than wide (length divided by width, 1.33 / 1.18).

Distribution. Japan (known from Muko-jima and Nakodo-jima Islands, Ogasawara-mura).

Remarks. Some Glenognatha species are unique to oceanic islands, such as G. hirsutissima and G. argenteoguttata, which seem to have differentiated into unique species after reaching the islands from the continent by long-distance dispersal a long time ago. Glenognatha osawai was also found 
on an oceanic island, but its uniqueness is unknown because the sample number is very small. Additional sampling and molecular phylogenetic analysis are necessary to evaluate its uniqueness and origin.

Although many faunal investigations have been performed on the Ogasawara Islands, G. osawai has not been found on large islands such as Haha-jima and Chichi-jima Islands, whereas it was found on the small islands Muko-jima and Nakodo-jima Islands, which have no human inhabitants. On Chichi-jima Island, the green anole (Anolis carolinensis), an invasive alien species of Reptilia, has dramatically reduced the abundance of terrestrial arthropods by predation (Toda et al. 2010), and the diversity of ground-dwelling spiders may be decreasing.

\section{Genus Pachygnatha Sundevall 1823}

Pachygnatha monticola sp. nov. (Japanese name: Yama-hime-ashinagagumo) (Figs. 10-18)

Type series. Holotype: đ̂, 10-X-1987, Togakushi, Nagano-shi, Nagano Prefecture, Japan. A. Tanikawa leg. Paratypes: $4 \widehat{\jmath} 5$, , the same data as for the holotype.

Etymology. The name is derived from the species' montane habitat.

Diagnosis. Pachygnatha monticola resembles $P$. quadrimaculata (Bösenberg \& Strand 1906) in general appearance but can be distinguished from the latter by the following traits: (1) dimples on the surface of chelicera are much more conspicuous in P. quadrimaculata than in P. monticola (Figs. 12, 14); (2) anterior row of cheliceral teeth with a gap about midway in $P$. monticola (Figs. 13, 15, arrow), but not in $P$. quadrimaculata; (3) male chelicera has an apophysis at the apical part of the anterior surface in $P$. quadrimaculata, but not in P. monticola (Figs. 12-13); (4) fang with small prominence in $P$. monticola (Figs. 12-13, arrows), but not in $P$. quadrimaculata; (5) embolus of the male palp is winding in P. quadrimaculata, but not in P. monticola (Fig. 16, e); (6) paracymbium of the male palp is long and finger shaped in $P$. monticola (Fig. 18, pc), but short in P. quadrimaculata.

Description. Based on holotype $\delta$ and paratype $1+$.

Coloration and markings. Male and female (Figs. 10-11): carapace brown; dorsum of abdomen light brown, mottled with white and black.

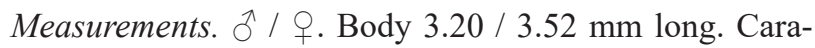
pace 1.38 / $1.53 \mathrm{~mm}$ long, $0.90 / 0.98 \mathrm{~mm}$ wide. Length of legs (tarsus + metatarsus + tibia + patella + femur $=$ total $):$ I, $0.75+1.35+1.56+0.41+1.55=5.62 \mathrm{~mm} / 0.80+1.45+$ $1.63+0.43+1.55=5.86 \mathrm{~mm} ; \mathrm{II}, 0.68+1.19+1.38+0.40$ $+1.45=5.10 \mathrm{~mm} / 0.73+1.28+1.29+0.43+1.55=5.28$ $\mathrm{mm}$; III, $0.45+0.74+0.73+0.33+1.00=3.25 \mathrm{~mm} / 0.48$ $+0.78+0.75+0.35+1.08=3.44 \mathrm{~mm} ; \mathrm{IV}, 0.53+0.71+$ $1.00+0.33+1.29=3.86 \mathrm{~mm} / 0.58+1.03+1.10+0.33+$
$1.38=4.42 \mathrm{~mm}$. Abdomen 1.73 / $1.80 \mathrm{~mm}$ long, 1.43 / 1.63 mm wide.

Male and female. Carapace longer than wide (length divided by width, 1.53 / 1.56). Median ocular area almost as long as wide (length divided by width, 0.95 / 0.92) and slightly wider behind than in front (anterior width divided by posterior width, $0.90 / 0.88$ ). Labium wider than long (length divided by width, $0.89 / 0.73$ ). Sternum almost as long as wide (length divided by width, $0.97 / 1.05$ ). Length of leg I divided by length of carapace 4.07 / 3.88. Male palp: embolus straight (Fig. 16), cymbium constricted near the middle (Fig. 17), paracymbium long and finger shaped (Fig. 18). Abdomen longer than wide (length divided by width, $1.21 / 1.11)$.

Distribution. Japan (known only from the type locality).

\section{Acknowledgements}

We thank Takeshi Osawa (Tokyo Metropolitan University,) and Yuki Murakami (Tokyo Metropolitan University) for their help in collecting the specimens used in the present study. We also thank Masayuki Ikuta and Noriaki Naya (University of Tsukuba) for their kind assistance in measurements and Takeshi Yamasaki (Tokyo Metropolitan University) for providing valuable comments on the manuscript. This work was supported by a grant from the Japan Society for the Promotion of Science KAKENHI, "Impacts of Eradication of Aliens on Island Ecosystems" (no. 16H01794).

\section{References}

Álvarez-Padilla, F. \& Hormiga, G. 2011. Morphological and phylogenetic atlas of the orb-weaving spider family Tetragnathidae (Araneae: Araneoidea). Zool. J. Linn. Soc-Lond., 162: 713-879.

Bösenberg, W. \& Strand, E. 1906. Japanische Spinnen. Abh. Senck. Naturf. Ges., 30: 93-422, pls. 3-16.

Cabra-Garcia, J. \& Brescovit, A. D. 2016. Revision and phylogenetic analysis of the orb-weaving spider genus Glenognatha Simon, 1887 (Araneae, Tetragnathidae). Zootaxa, 4069: 1-183.

Ito, M. 1998. Origin and evolution of endemic plants of the Bonin (Ogasawara) Islands. Res. Popul. Ecol., 40: 205-212.

Pickard-Cambridge, O. 1876. Catalogue of a collection of spiders made in Egypt, with descriptions of new species and characters of a new genus. Proc. Zool. Soc. London, 44(3): 541-630, pls. LVIIILX.

Tanikawa, A. 2009. Tetragnathidae. Pp. 405-419. In: Ono, H. (ed.) The Spiders of Japan with Keys to the Families and Genera and Illustrations of the Species. Tokai University Press, Kanagawa, xvi + 738 pp. (In Japanese)

Tanikawa, A. 2017. A Check List of Japanese Spiders ver. 2017R1. online at http://www.asahi-net.or.jp/ dp7a-tnkw/japan.pdf, accessed on June 5, 2017. (In Japanese)

Toda, M., Takahashi, H., Nakagawa, N. \& Sukigara, N. 2010. Ecology and control of the green anole (Anolis carolinensis), an invasive alien species on the Ogasawara Islands. Pp. 145-152. In: Kawakami, K. \& Okochi, I. (eds.) Restoring the Oceanic Island Ecosystem. Springer Japan, Tokyo, 216 pp.

World Spider Catalog 2017. World Spider Catalog. Version 18.5. Natural History Museum, Bern. Available at http://wsc.nmbe.ch, accessed on November 20, 2017.

Zhu, M. S., Song, D. X. \& Zhang, J. X. 2003. Fauna Sinica: Invertebrata Vol. 35: Arachnida: Araneae: Tetragnathidae. Science Press, Beijing, vii +418 pp.

Received November 27, 2017 / Acceoted January 10, 2018 